\title{
An Empirical Study of Cost of Milk Production in Timergara District Dir, Pakistan
}

\author{
Altaf Hussain ${ }^{1}$, Fayaz Ali Shah ${ }^{2}$, Jawad Hussain ${ }^{3}$ \\ ${ }^{1,2,3}$ (PhD Student, Faculty of Management and Human resource Development, University Technology \\ Malaysia).
}

\begin{abstract}
This study was conducted in Timergara District Dir (Lower) Pakistan to estimate the cost of milk production. The methodology used for this study is mainly quantitative. Data was collected through questionnaire from a sample size of 80 farmers in the town of Timergara. The cubic cost function model was used to analyze the collected data. The study shows that average values of dry and milking buffaloes were 2 and 42 respectively while the average milk production per buffalo was 0.11 mounds $(5.5 \mathrm{~kg})$. The major cost components of milk production were green fodder, dry fodder, concentrates, medicines, management, equipment, building and other miscellaneous. The total fixed cost (TFC) and average variable cost (AVC) per farm was 39761 and 468.51 rupees respectively. The marginal cost (MC) was minimum at output level 680 and the average variable cost (AVC) was minimum at i.e. Rs.468. The optimal level of milk production was 1232 mounds $(61600 \mathrm{~kg})$. The results show that none of the sampled farmers operated at the optimum level of operation.
\end{abstract}

Keywords: Cost, Milk, Pakistan, Production, Return, Timergara,

\section{Introduction}

The importance of livestock sector in Pakistan's agriculture is not limited to the production of milk and milk products only, since it provides income and food to a significant portion of the population. Consumption of milk and milk products in the country is relatively high as compared to other similar developing countries. The livestock also provides high quality protein. The major milk-producing animals in Pakistan are buffaloes, cows, sheep and goats. However almost all the milk marketed in the country comes from buffaloes and cows. The population of buffaloes, cows, sheep and goats is 30.8 millions, 34.3 millions, 27.8 millions and 59.9 millions respectively (GOP, 2009-10).

Livestock contributes 11.4\% to GDP (GOP, 2009-10). Its net foreign exchange earnings were to the tune of Rs. 39.5 billion in 2008-2009, which is almost $9 \%$ of the overall export earnings of the country. The contribution of livestock sector towards GDP is more than any individual major crop. The role of livestock in rural economy may be realized from the fact that 30-35 million rural populations is engaged in livestock raising, having household holdings of 2-3 cattle/buffaloes and 5-6 sheep / goats per family deriving 30-40\% of their income from it (GOP, 2009-10). Milk, beef, mutton, poultry and eggs are the major livestock products. However, in terms of retail value, milk is the most important livestock product in Pakistan.

Being the $6^{\text {th }}$ or $7^{\text {th }}$ largest milk producer in the world, Pakistan is not self sufficient in milk and therefore every year a significant amount of foreign exchange is spent on the import of dairy products mainly dry milk powder and condensed and evaporated milk.

Dairying is considered to be a supplementary enterprise to crop production and therefore the problems relating to milk production have never engaged the serious attention of researchers. The objective of achieving self-sufficiency in food has led the policy makers and researchers to focus their attention on increasing the output of major food crops. Consequently, the milk production and marketing system have not been researched adequately in Pakistan. A few studies (Mahmood, 1997 and Khan 1999) pertaining to milk production and marketing have been carried out, however these too are limited in scope and analysis. Additionally, most of these studies are limited to Punjab province with one exception by Khan (1999).

As for as the scope of livestock sector is concerned in Khyber Pakhtunkhwa (KPK), it is relatively more important than livestock in the province of Punjab and Sindh. Punjab and Sindh have relatively more plain land with good irrigation system and also these provinces have relatively good industrial base. KPK however has mountainous zones particularly in the northern part of the province. These hilly areas are although not that much suitable for crops but more appropriate for livestock.

As reported earlier research studies pertaining to milk production and marketing are scarce in Pakistan. The situation in KPK is even worse. Keeping in view the deficiencies in available literature, the study in hand is an attempt to fill these gaps. 


\section{Objectives Of The Study}

- To study the milk production system on the basis of costs and returns from dairying.

- To identify various factors influencing marketed surplus of milk.

- To suggest recommendations on the basis of the findings of the research in order to improve the milk production system in Pakistan in general and District Dir in particular.

\section{Review Of Literature}

Khan (1999) carried out a research study pertaining to the economics of milk production and marketing in Peshawar District. He analyzed the milk production and marketing system in the study area and found that almost all the milk producers in Peshawar operate at lower than optimum level of operation and recommended that these producers shall better expand their operation in order to minimize their costs and increase revenue in terms of milk distribution. It was added that adulteration is the major problem since water is added to milk almost at all stages while traveling along the chain of distribution including the producers. In term of revenue it was reported that actual marketing margin is much higher than the perceived ones due to dilution.

Khan et al. (1998) examined the strategies and efficiency milk production systems in Peshawar District, KPK, Pakistan. Their findings are that much of the milk produced in Peshawar District is from the buffalo. In terms of total milk production, the major contribution i.e. $46 \%$ comes from large farms, followed by medium farms, which produced $36 \%$ of the total milk. The results show that large farms are cost efficient. It was also found that $50 \%$ of the small farms and $13 \%$ of the medium farms incurred losses whereas no large farm fell within this category. Furthermore, the results show that the net income per animal is significantly different between the three categories of farms.

Bouquiaux and Hellemans (1998) conducted a research in Belgium and discussed the impacts of milk quotas and production structures. They reported that milk production has been falling since 1983 whilst consumption has been increasing since 1980. Profitability of dairy farms increased by more than $30 \%$ over the 1986/87-93/94 period. There has been an increase in capital invested, a reduction in solvency percentage and an increase in production costs. When compared to other dairy sectors within the EU, Belgian dairy farms work comparatively efficiently.

Chaudhry et al. (1997) conducted a study in Okara, Punjab, Pakistan during 1992-93.The respondents were selected using the stratified random sampling techniques. There was variation in the lactation period among the farm categories. Average milk yield was 3266.66, 2667.20 and 3140.87 litres/lactation for categories (i) -(iii) respectively. A wide fluctuation, both within and across the farms occurred in the summer and winter milk yield. The cost of milk production of commercial producers was the lowest where as that of subsistent being the highest. Costs/litre milk was Rs 3.9, 3.7 and 3.2 for subsistent, Semi-commercial, Commercial producers, respectively. Commercial producers were able to sell their milk at prices higher than subsistent and semi-commercial farmers (Rs 5.00 vs. 4.25 and 4.25 per $\mathrm{kg}$ ). Consequently, the third category i.e. commercial producers realized, higher sale receipts/milch animal. The benefit cost ratio varied inversely with the operational size of the milk production unit. They concluded that there had been little or no shift in the functional and size distribution of the cost structure over time.

Kalra et al. (1995) carried out an economic analysis of data collected from 128 milk producing households in Haryana, India, and reported that the maintenance cost of buffaloes, cross-bred cows and local cows was Rs 19.11, Rs 20.25 and Rs 14.22 per day per animal respectively. The milk production of local cows resulted in a net loss of Rs 3.82/day. Fixed costs represented $85 \%$ of the total costs and variable costs accounted for $15 \%$. The cost of producing milk was Rs 4.95 , Rs 3.53 and Rs 6.91 per litre for buffalo, crossbred and local cows, respectively. Milk producers consumed $44.7 \%$ of the buffalo milk and $5.25 \%$ of the cow milk produced. 37.6 and $83.8 \%$ of buffalo and cow milk respectively was sold to milk vendors and 8.67 and $2.88 \%$ was sold to the milk producers' cooperative societies.

Singh et al. (1995) carried out a research study in the Kurukshetra and Karnal Districts of Haryana, India, and examined the expenditure and income of 400 dairy farm families from 16 villages over three seasons during 1991-93. Families were divided into five categories on the basis of land holdings. Expenditure on feed and labour was $49.7 \%$ and $19.96 \%$ of the total expenditure (Rs 10113855) respectively. Expenditure increased with increase in farm size. The variable and fixed costs were approximately $70.03 \%$ and $29.96 \%$ of total expenditure respectively. Feed and labour charges were $70.92 \%$ and $28.50 \%$ of the variable cost. The overall economic efficiency was $3.45 \%$, but for Kurukshetra it was low (1.02\%) compared with 5.75\% for Karnal. Values were negative for the landless and marginal categories.

Sharma and Singh (1994) calculated the costs and returns from different breeds of dairy animals on different categories of farmers in the humid-temperature zone of Himachal Pradesh, India. The average cost of maintenance per annum of crossbred cows, local cows, graded-Murrah buffaloes and local buffaloes were Rs $3624.55,1981.95,4161.00$ and 2584.20 respectively, yielding a gross income of Rs 5099.48, 2013.32, 6069.62 and 3385.65 in the same order. The operational cost was approximately $85 \%$ of total cost and fixed costs accounted for only 15\%. The crossbred cows and graded-Murrah buffaloes gave a net income of Rs 1613.64 and 
2072.87 respectively. However, net income per annum for local cow and local buffaloes was only Rs.127.62 and 925.55 respectively. The findings indicate that it is more profitable vigorously to follow a crossbreeding programme for improving the potentiality of local cows, whereas in the case of buffaloes, the selection of highyielding breeds will greatly augment present-day milk production in Himachal Pradesh.

Dev et al. (1994) investigated the seasonal cost of milk production for local cows and nondescript buffaloes, and net returns from milk production, using data obtained from (i) 14 landless labourers and (ii) 22 marginal ( $<8$ acres), (iii) 29 small (8-16 acres) and (iv) 39 large ( $>16$ acres) farmers in 2 villages of Rajgarh Tehsil in the arid Churu district of Rajasthan, India. The overall cost of milk production (in Rs/litre) of buffaloes and cows respectively was (i) 5.38 and 6.76, (ii) 5.37 and 6.42, (iii) 5.46 and 6.15 and (iv) 5.56 and 6.32, with overall mean of 5.44 and 6.38. Cost of milk production showed considerable seasonal variation in all groups. The net returns from milk production were negative, except for buffalo milk in winter from landless labourers, marginal, small and large farmers. If cost of family labour was excluded, the overall net returns from milk production became positive for buffalo milk in winter and pooled seasons (Rs 1.01 and $0.19 /$ litre respectively) and for cow milk in the rainy season (Rs $0.03 /$ litre). It is concluded that rearing of indigenous cows in this region is more uneconomic than that of buffaloes.

Khan (1992) analyzed the data collected by Abid (1988) on the economics of milk production and marketing in District Thatta, Sindh, Pakistan. Mr. Khan analyzed the data collected by Abid (1988). He estimated the duel cost function for milk production and reported that economies of scale exist in certain cases. For small farms output of milk is the most important determinant of the dual cost, whereas in case of medium farms variable inputs such as price of dry fodder, and price of oilcake played a crucial role in the determination of dual cost. However, for large farms price of green fodder and oilcake are the important variable inputs that determine the dual cost.

\section{Methodology}

This study was conducted in Tamergara of District Dir. Timergara is the capital of Lower District Dir. The socio-economic feature of Timergara is such that milk producers are scattered all over the town. Since, almost all the milk producers in Timergara and its suburbs carry out dairying on commercial lines. Therefore, this town was purposively selected for this study. In order to give representation to the entire town, it is divided into north, south, east and west. Keeping in view the limited resources and time in hand, a sample of 80 farmers was selected on random basis.

Data was collected through questionnaire from the above mentioned sample of farmers. The data collected was analyzed by using various econometric and statistical techniques in order to reach meaningful conclusions. Total cost was computed simply by adding cost of labour, green fodder, dry fodder, concentrates, medicine, management, buildings, equipments, utensils and miscellaneous cost.

Cost analysis was used to see the relationship between cost and quantity of milk produced. Cost function analysis has been widely used to analyze the cost structure of various enterprises. In this study the following cubic cost function was used to analyze the cost structure of milk producers in the study area.

$\begin{array}{clll}\mathrm{TC}= & \beta+\beta_{1} \mathrm{Q}+\beta_{2} \mathrm{Q}^{2}+\beta_{3} \mathrm{Q}^{3}+\mathrm{U}_{\mathrm{i}} \\ \text { Where } & \mathrm{TC}= & \text { Total Production cost } \\ \mathrm{Q} & = & \text { Level of output in Mounds } \\ \mathrm{U}_{\mathrm{i}} & = & \text { Stochastic Term } \\ \beta & = & \text { Intercept } \\ \beta_{1}, \beta_{2}, \beta_{3} & = & \begin{array}{l}\text { Slope coefficients and based on economic theory } \\ \text { they must fulfill the following restrictions; }\end{array} \\ 3, \beta 1, \beta_{3},>0, \beta_{2}<0 \text { and } \beta_{2}{ }^{2}<3 \beta_{1} \beta_{3} \text { (Gujrati, 1988) }\end{array}$

\section{V.I. Distribution of Dry and Milking Buffaloes}

\section{Results And Discussions}

Distribution of dry and milking buffaloes are given in Table 1 . The total average number of dry buffaloes in the north, south, east and west Timergara was 20 each. Whereas this value for milking buffaloes in the research area was 42 . The average value of dry buffaloes in the north and south Timergara was 2 whereas this value in the west Timergara was 1 and 1 in the east Timergara. The average value of milking buffalo in the east Timergara was 72 , which was high as compared to the other average values of milking buffaloes in the north, south and west Timergara. 
An Empirical Study of Cost of Milk Production in Timergara District Dir, Pakistan

Table 1 Distribution of Dry and Milking Buffaloes.

\begin{tabular}{|c|c|c|c|}
\hline \multicolumn{2}{|c|}{ Research site } & D. Buffaloes & M. Buffaloes \\
\hline North Timergara & Mean & 2 & 12 \\
& Std Deviation & 3 & 32 \\
\hline South Timergara & Mean & 2 & 6 \\
\hline West Timergara & Std Deviation & 4 & 52 \\
& Mean & 1 & 6 \\
\hline East Timergara & Std Deviation & 2 & 72 \\
& Mean & 1 & 6 \\
\hline Ttd Deviation & Mean & 2 & 42 \\
& Std Deviation & 3 & 23 \\
\hline
\end{tabular}

\section{V.II. Milk Quantity and Number of Animals in the Research Area}

Table 2 shows milk quantity and number of animals in the research area. The average number of animal was 4 having average milk production 0.44 mounds. Average milk production and standard deviation was high in south Timergara whereas there was slight difference in the other average values and standard deviation in the north, west and east Timergara. The average number of animals in the north, south and west Timergara was also 4 whereas this value was different in east Timergara i.e. 3 .

Table.2 Milk Quantity and Number of Buffaloes in the Research Area

\begin{tabular}{|c|c|c|c|}
\hline \multicolumn{2}{|c|}{ Research site } & Milk Quantity (mounds) & No. of Buffaloes \\
\hline \multirow[t]{2}{*}{ North Timergara } & Mean & 0.44 & 4 \\
\hline & Std Deviation & 0.24 & 3 \\
\hline \multirow[t]{2}{*}{ South Timergara } & Mean & 0.52 & 4 \\
\hline & Std Deviation & 0.7 & 7 \\
\hline \multirow[t]{2}{*}{ West Timergara } & Mean & 0.34 & 4 \\
\hline & Std Deviation & 0.26 & 3 \\
\hline \multirow[t]{2}{*}{ East Timergara } & Mean & 0.46 & 3 \\
\hline & Std Deviation & 0.32 & 3 \\
\hline \multirow[t]{2}{*}{ Total } & Mean & 0.44 & 4 \\
\hline & Std Deviation & 0.42 & 4 \\
\hline
\end{tabular}

\section{V.III. Distribution of Small, Medium and Large Respondents}

Table 3 shows distribution of sampled respondents in small, medium and large categories. The maximum (63\%) number of respondents was large followed by small (21\%) and medium (16\%). As for as land size is concerned east Timergara, large category having 14 sattas (local scale for measurement of land) of land while the range of land size in north, south and west Timergara in the large category was 11, 12 and 13 (sattas) respectively.

Table.3 Distribution of Small, Medium and Large Respondents

\begin{tabular}{|c|c|c|c|c|}
\hline \multirow{2}{*}{ Research Site } & \multicolumn{2}{|c|}{ Different Categories of Respondents } & \multirow{2}{*}{ Total } \\
\cline { 2 - 4 } & Small & Medium & Large & \\
\hline North Timergara & 5 & 4 & 11 & 20 \\
\hline South Timergara & 4 & 4 & 12 & 20 \\
\hline West Timergara & 5 & 2 & 13 & 20 \\
\hline East Timergara & 3 & 3 & 14 & 20 \\
\hline Total & 17 & 13 & 50 & 80 \\
\hline \%age & 21 & 16 & 63 & 100 \\
\hline
\end{tabular}

\section{V.IV. Distribution of Buffalo's Prices}

Table 4 shows the distribution of buffalo's prices. It reveals that 26 of the respondents of the research area gave 22500 rupees for one buffaloes. Whereas other respondents gave different prices of buffaloes ranging from 18000-30000 rupees. The total average price of buffaloes in the research area was 23518 rupees whereas the minimum and maximum prices of buffaloes were 18000 and 30000 rupees. 


\begin{tabular}{|c|c|c|c|}
\hline Trice & Frequency & Percent & Cumulative percent \\
\hline 18000 & 8 & 10.0 & 10.0 \\
\hline 19000 & 7 & 8.8 & 18.8 \\
\hline 21000 & 6 & 7.5 & 26.3 \\
\hline 22500 & 26 & 32.5 & 58.8 \\
\hline 23000 & 7 & 8.8 & 67.5 \\
\hline 26000 & 5 & 6.3 & 73.8 \\
\hline 27500 & 11 & 13.8 & 87.5 \\
\hline 30000 & 10 & 12.5 & 100 \\
\hline Total & 80 & 100 & \\
\hline Minimum & & 18000 & \\
\hline Maximum & & 30000 & \\
\hline Mean & & 23518 & \\
\hline
\end{tabular}

\section{V.V. Green Fodder Cost}

Table. 5 shows green fodder cost of the sampled respondents. On average 406 and 688 mounds of maize and shaftal (name of local grass) was given to animals in the research area. There was very light difference between the average maize quantity in west and east Timergara whereas such difference was very high in case of north and south Timergara. The variation for shaftal in all of the four sites as well as on the whole was very minimum. The average per year cost of maize was very high in south Timergara, while there was little bit difference in such cost in west, north and east of the research area. This could be due to the huge quantity of maize feed in south Timergara.

Table.5 Green Fodder Cost

\begin{tabular}{|c|c|c|c|c|}
\hline Research Site & $\begin{array}{l}\text { Maize quantity } \\
\text { Mounds/year }\end{array}$ & $\begin{array}{l}\text { Maize per year } \\
\text { cost }\end{array}$ & $\begin{array}{l}\text { Shaftal quantity } \\
\text { mounds/year }\end{array}$ & $\begin{array}{l}\text { Shaftal per } \\
\text { year cost }\end{array}$ \\
\hline North Timergara Mean & 390 & 19320 & 688 & 23900 \\
Std Deviation & 173 & 8431 & 303 & 11106 \\
\hline South Timergara Mean & 488 & 24780 & 737 & 26050 \\
Std Deviation & 506 & 25689 & 596 & 21358 \\
\hline West Timergara Mean & 377 & 18980 & 679 & 24050 \\
Std Deviation & 200 & 10267 & 434 & 16580 \\
\hline East Timergara Mean & 367 & 18400 & 649 & 22750 \\
Std Deviation & 175 & 9167 & 355 & 12949 \\
\hline Mean & 406 & 20370 & 688 & 24188 \\
Stal Deviation & 297 & 15101 & 429 & 15724 \\
\hline
\end{tabular}

\section{V.VI. Quantity and Cost of Dry Fodder}

Table 6 shows that on the average total quantity of Bhussa and Palala (Dry fodder) in the research area given to the animals were 125 mounds and 114 mounds respectively. There was very slight difference between the average quantities of Bhussa in the north and west Timergara where as such differences were very high in case of east and south Timergara. There was slight variation in the average quantities of Palala in north, south and east Timergara respectively whereas the average quantity of Palala in the west Timergara was very high. The total average cost of Bhussa and Palala were 15013 rupees and 11991 rupees respectively. There were very slight differences in the average cost of Palala in the north and east Timergara whereas the differences in the average cost of Palala in the south and west were high. The difference was high because of the huge quantities used by the buffaloes in the south and west Timergara.

Table 6 Quantity and Cost of Dry Fodder

\begin{tabular}{|c|c|c|c|c|}
\hline Research Site & $\begin{array}{l}\text { Quantity of } \\
\text { Bhussa in } \\
\text { mounds per year }\end{array}$ & $\begin{array}{l}\text { Cost of Bhussa } \\
\text { per year }\end{array}$ & $\begin{array}{l}\text { Quantity of } \\
\text { Palala per year }\end{array}$ & $\begin{array}{l}\text { Cost of } \\
\text { Palala per } \\
\text { year }\end{array}$ \\
\hline North Timergara Mean & 125 & 15025 & 102 & 10680 \\
Std Deviation & 44 & 5401 & 46 & 4767 \\
\hline South Timergara Mean & 132 & 16000 & 117 & 12325 \\
Std Deviation & 99 & 12039 & 117 & 12426 \\
\hline West Timergara Mean & 123 & 14825 & 141 & 14830 \\
Std Deviation & 49 & 5939 & 117 & 12357 \\
\hline
\end{tabular}


An Empirical Study of Cost of Milk Production in Timergara District Dir, Pakistan

\begin{tabular}{|c|c|c|c|c|}
\hline $\begin{array}{c}\text { East Timergara } \\
\text { Std Deviation }\end{array}$ & $\begin{array}{c}118 \\
71\end{array}$ & $\begin{array}{l}14200 \\
8749\end{array}$ & $\begin{array}{l}96 \\
50\end{array}$ & $\begin{array}{c}10130 \\
5523\end{array}$ \\
\hline $\begin{array}{ll}\text { Total } & \text { Mean } \\
& \text { Std Deviation } \\
\end{array}$ & $\begin{array}{c}125 \\
68 \\
\end{array}$ & $\begin{array}{c}15013 \\
8318 \\
\end{array}$ & $\begin{array}{c}114 \\
90\end{array}$ & $\begin{array}{c}11991 \\
9489 \\
\end{array}$ \\
\hline
\end{tabular}

\section{V.VII. Quantity and Cost of Concentrates}

Table 7 shows the quantity of cost of concentrates feed to the animals. The total average quantity of khal (cotton seed cakes) in the research area was 68 mounds whereas the total average quantity of Bura in the research area was 77 mounds. The average quantity of Khal in the north, south, west and east was 77, 88, 60 and 48 mounds respectively. There was little variations in the average quantities of khal in the research area. The average quantity of Bura in south Timergara was very high (112 mounds) where as there was slight variation in the average quantities of Bura in the north, west and east Timergara. The average cost of Bura in the south Timergara was very high (33507 rupees) whereas there was slight variation in the average cost of Bura in the north, west and east Timergara. The average cost of Bura in the south Timergara was very high because the average quantity of Bura in the south Timergara was huge. The total average cost of Bura in the research area was 23036 rupees.

Table 7 Quantity and Cost of Concentrates

\begin{tabular}{|c|c|c|c|c|}
\hline Research Site & $\begin{array}{l}\text { Quantity of Khal } \\
\text { in mounds per } \\
\text { year }\end{array}$ & $\begin{array}{l}\text { Cost of Khal } \\
\text { mounds per year }\end{array}$ & $\begin{array}{l}\text { Quantity of Bura } \\
\text { in mounds per } \\
\text { year }\end{array}$ & $\begin{array}{l}\text { Cost of Bura } \\
\text { in mounds per } \\
\text { year }\end{array}$ \\
\hline North Timergara Mean & 77 & 38325 & 78 & 23488 \\
\hline Std Deviation & 49 & 24571 & 57 & 17209 \\
\hline South Timergara Mean & 88 & 44165 & 112 & 33508 \\
\hline Std Deviation & 145 & 72756 & 239 & 71614 \\
\hline West Timergara Mean & 60 & 28839 & 66 & 19765 \\
\hline Std Deviation & 63 & 31545 & 69 & 20570 \\
\hline East Timergara Mean & 48 & 24181 & 51 & 15385 \\
\hline Std Deviation & 58 & 29007 & 62 & 18645 \\
\hline $\begin{array}{cr}\text { Total } & \text { Mean } \\
& \text { Std Deviation }\end{array}$ & $\begin{array}{l}68 \\
88\end{array}$ & $\begin{array}{l}34128 \\
43814\end{array}$ & $\begin{array}{c}77 \\
131\end{array}$ & $\begin{array}{l}23036 \\
39184\end{array}$ \\
\hline
\end{tabular}

\section{V.VIII. Cost other than Fodder and Concentrates}

Cost other than fodder and concentrate is given in Table 8. Average cost of medicine, management, equipment and utensils, building and miscellaneous were 4553, 376, 327, 2783 and 19128 rupees, respectively. There was slight variation in the average costs of medicine in the north, south, east and west Timergara. The average cost management in the west Timergara was high whereas there was slight variation in the average cost of management in the north, south and east Timergara respectively. The average miscellaneous cost in the south Timergara was 20775 rupees whereas there was slight variation in the average miscellaneous cost in the north, west and east Timergara. There was little bit difference in the average cost of building in the four site of the research area.

Table 8 Cost other than Fodder and Concentrates

\begin{tabular}{|l|l|l|l|l|l|}
\hline Research Site & $\begin{array}{l}\text { Cost medicine } \\
\text { per year }\end{array}$ & Cost of management & $\begin{array}{l}\text { Cost of } \\
\text { equipment and } \\
\text { utensils }\end{array}$ & $\begin{array}{l}\text { Cost of } \\
\text { building/year }\end{array}$ & $\begin{array}{l}\text { Masc. } \\
\text { cost }\end{array}$ \\
\hline $\begin{array}{l}\text { N.Timergara Mean } \\
\text { Std Deviation }\end{array}$ & 4710 & 362.8500 & 331.2500 & 2255.6000 & 18860 \\
& 2359 & 99.5771 & 111.1764 & 260.8333 & 19291 \\
\hline S. Timergara & & & & & \\
Mean & 5375 & 370.2500 & 373.7500 & 3416.7000 & 20775 \\
Std Deviation & 5183 & 94.1650 & 296.7450 & 2817.1236 & 23460 \\
\hline W. Timergara & & & 300.0000 & 2533.3500 & 18300 \\
Mean & 4150 & 411.0000 & 105.7554 & 1618.8067 & 19141 \\
Std Deviation & 1960 & 85.6953 & 302.5000 & 2927.8000 & 18575 \\
\hline E. Timergara & & & 132.3522 & 1910.3346 & 20463 \\
Mean & 3975 & 361.5000 & 326.8750 & 2783.3625 & 19127 \\
Std Deviation & 24100 & 80.9987 & 178.7410 & 1998.0387 & 20289 \\
\hline Total Mean & 4553 & 376.4000 & 90.9769 & \\
Std Deviation & 3245 & &
\end{tabular}




\section{V.IX. Division of Family Labor}

Table 9 shows division of family labors of the research site. Average value of male family labour, female labour and child family labour was 2, 1 , and 1 respectively. The average value of male family labour in the north and west Timergara was 2 whereas the average value of male family labour in the east and south Timergara was one, respectively. Average value of family child labour in the research site was almost same (1). The total average cost of labour in the research area was 84465 rupees. There was slight difference in the average cost of labour in the north, south and west Timergara whereas the average cost in east Timergara was very low (62820 rupees). The average cost in east Timergara was very low because the average value of labors in the east Timergara was low.

Table 9 Division of Family Labour

\begin{tabular}{|c|c|c|c|c|}
\hline Research Site & $\begin{array}{c}\text { Male family } \\
\text { labour }\end{array}$ & $\begin{array}{c}\text { Female family } \\
\text { labour }\end{array}$ & $\begin{array}{c}\text { Number of family } \\
\text { children labour }\end{array}$ & $\begin{array}{c}\text { Cost of labour } \\
\text { (Rs) }\end{array}$ \\
\hline North Timergara Mean & 2 & 2 & 1 & 99360 \\
Std Deviation & 1 & 1 & 1 & 42778 \\
\hline South Timergara Mean & 2 & 2 & 1 & 81900 \\
Std Deviation & 1 & 1 & 1 & 35578 \\
\hline West Timergara Mean & 2 & 2 & 1 & 93780 \\
Std Deviation & 1 & 1 & 1 & 39651 \\
\hline East Timergara Mean & 2 & 1 & 1 & 62820 \\
Std Deviation & 1 & 1 & 1 & 84701 \\
\hline Total Mean & 2 & 2 & 1 & 38802 \\
Std Deviation & 1 & 1 & 1 & \\
\hline
\end{tabular}

\section{V.X. Cubic Cost Function}

Cubic cost function is widely used in such type of analysis (Elhendy and Alzoom 2001, Khan 1999), therefore cubic cost model was used to analyze the cost structure of the selected milk producers in this study. The relationship between total cost and output resembles the elongated S curve; notice how the total cost curve first increases gradually and then rapidly, as predicted by the celebrated law of diminishing returns. This $\mathrm{S}$ shape of the total cost curve can be captured by the following cubic cost function.

$\mathrm{TC}=\beta+\beta_{1} \mathrm{Q}+\beta_{2} \mathrm{Q}^{2}+\beta_{3} \mathrm{Q}^{3}+\mathrm{U}_{\mathrm{i}} \ldots \ldots \ldots \ldots \ldots \ldots \ldots \ldots \ldots$ (A)

Where TC $=$ total cost, $\mathrm{Q}$ is the level of output and $\beta, \beta_{1}, \beta_{2}$, and $\beta_{3}$ are the parameters of total cost and $\mathrm{U}_{\mathrm{i}}$ is the stochastic term.

According to Chiang (1984), the parameters of equation A must satisfy the following restriction if one is to observe the typical $\mathrm{U}$-shaped short run marginal and average cost curves.

$\beta, \beta_{1}, \beta_{3}>0, \beta_{2}<0$, and $\beta_{2}{ }^{2}<3 \beta_{1} \beta_{3}$

Therefore, equation $A$ can be rewritten as:

$\mathrm{TC}=\beta+\beta_{1} \mathrm{Q}-\beta_{2} \mathrm{Q}^{2}+\beta_{3} \mathrm{Q}^{3}+\mathrm{U}_{\mathrm{i}}$

The same cost function with no intercept/constant can be written as

$\mathrm{TC}=\beta_{1} \mathrm{Q}-\beta_{2} \mathrm{Q}^{2}+\beta_{3} \mathrm{Q}^{3}+\mathrm{U}_{\mathrm{i}}$

\section{V.XI. Results of Regression Analysis (Cubic Cost Function)}

The total cost function (Equation A) was regressed using OLS technique. It was regressed with constant option.

The results are given below.

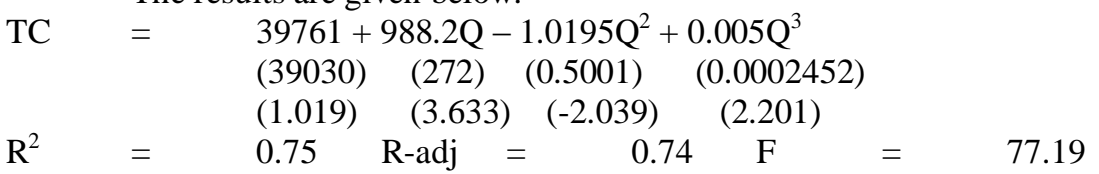

The figures in first and second parenthesis represent standard error and t-ratios respectively. The coefficient of estimated cost function had the anticipated sign. The value of the co-efficient of determination i.e. $\mathrm{R}^{2}$ reveals that the cubic cost model is the best fit and the independent variable i.e. $Q$ explains variations in total cost.

\section{V.XII. Mathematical Analysis of Cubic Cost Functions}

The key decision like enterprise expansion, optimal use of resources and staying in business depends on average variable cost (AVC), average total cost (ATC) and marginal cost (MC). Therefore, the AVC, ATC and $\mathrm{MC}$ functions are derived from TC function in the following paragraphs.

$\mathrm{TC}=0.0005 \mathrm{Q}^{3}-1.0195 \mathrm{Q}^{2}+988.2 \mathrm{Q}+39761--\mathrm{A}$.

$\mathrm{TFC}=39761$ 
$\mathrm{TVC}=\mathrm{TC}-\mathrm{TFC}$

$\mathrm{TVC}=0.005 \mathrm{Q}^{3}-1.0195 \mathrm{Q}^{2}+988.2 \mathrm{Q}$

$\mathrm{AVC}=\mathrm{TVC} / \mathrm{Q}$

$\mathrm{AVC}=0.0005 \mathrm{Q}^{2}-1.0195 \mathrm{Q}+988.2$

Now in order to estimate the level of output at which the AVC is minimum, the AVC is differentiated with respect to $\mathrm{Q}$ and put equal to zero (first order necessary condition).

(C) $\Rightarrow$ AVC $=0.0005 Q^{2}-1.0195 \mathrm{Q}+988.2$

$$
\begin{aligned}
& \frac{\partial \mathrm{AVC}}{\partial \mathrm{Q}}=1 \times 10^{-3} \mathrm{Q}-1.0195=0(\mathrm{FONC}) \\
& \mathrm{Q}=1019.5
\end{aligned}
$$

Hence at $\mathrm{Q}=1019.5$ mounds of milk, the AVC is minimum. Now in order to find that minimum AVC, put the value of $\mathrm{Q}=1019.5$ in eq $(\mathrm{C})$

(C) $\Rightarrow \mathrm{AVC}_{\mathrm{atQ}}=1019.5=0.0005(1019.5)^{2}-1.0195(1019.5)+988.2$

$$
=468.51
$$

To estimate the level of output at which MC is minimum, the MC was differentiated with respect to $\mathrm{Q}$ and put equal to zero.

From eq B we know that

$\mathrm{MC}=1.5 \times 10^{-3} \mathrm{Q}^{2}-2.039 \mathrm{Q}+988.2$

$$
\begin{gathered}
\frac{\partial M C}{\partial Q}=3 \times 10^{-3} Q-2.039=0(F O N C) \\
Q=679.66
\end{gathered}
$$

Thus its is found that MC is minimum at

$\mathrm{Q}=679.66$ level of output.

(B) $\quad \Rightarrow \quad \mathrm{Mc}_{\text {at }} \mathrm{Q}=679.66=1.5 \times 10^{-3}(679.66)^{2}-2.039(679.66)+988.2$

$=295.28$

Additionally from cost theory under perfect competitive market we know that MC passes through the lowest of AVC and ATC curves, therefore, MC are equal to AVC \& ATC when AVC and ATC are minimum. From equation $\mathrm{D}$ we know that $\mathrm{AVC}$ is minimum when $\mathrm{Q}=1019.5$, so putting this value in eq $\mathrm{B}$ i.e. $\mathrm{MC}$ function.

$$
\mathrm{MC}_{\text {at } \mathrm{Q}=1019.5}=1.5 \times 10^{-3}(1019.5)^{2}-2.039(1019.5)+988.2=468.51
$$

Hence it is proved that $\mathrm{AVC}=\mathrm{MC}$ level of output at which AVC is minimum. Therefore, the 468.51 is the minimum AVC per mound of milk when level of output is 1019.5.

From definition of ATC, we know that,

$$
\begin{aligned}
& \mathrm{ATC}=\frac{\mathrm{TC}}{\mathrm{Q}} \\
& \text { (A) } \Rightarrow \mathrm{TC}=0.0005 \mathrm{Q}^{3}-1.0195 \mathrm{Q}^{2}+988.2 \mathrm{Q}+39761 \\
& A T C=\frac{T C}{Q} \quad \frac{\mathrm{TC}=0.0005 \mathrm{Q} 3-1.0195 \mathrm{Q} 2+988.2 \mathrm{Q}+39761}{Q} \\
& =0.0005 \mathrm{Q}^{2}-1.0195 \mathrm{Q}+988.2+\frac{39761}{\mathrm{Q}}(\mathrm{E})
\end{aligned}
$$

The level of output at which ATC is minimum, the slope of ATC is equal to zero. Therefore, differentiating ATC with respect to Q and putting equal to zero will give the value of Q at which ATC is minimum.

$$
\begin{aligned}
& \text { (E) } \quad A T C=0.0005 Q^{2}-1.0195 Q+988.2+\frac{39761}{Q} \\
& \frac{\partial \mathrm{ATC}}{\partial \mathrm{Q}}=1 \times 10^{-3} \mathrm{Q}-1.0195-39761 \mathrm{Q}^{-2}=0(\mathrm{FONC})
\end{aligned}
$$


$=1 \times 10^{-3} \mathrm{Q}-1.0195-\frac{39761}{\mathrm{Q}^{2}}=0$

$\frac{1 \mathrm{X} 10^{-3} \mathrm{Q}^{3}-1.0195 \mathrm{Q}^{2}-39761}{\mathrm{Q}^{2}}=0$ Taking $\mathrm{Q}^{2} \mathrm{LCM}$

$=1 \mathrm{X} 10^{-3} \mathrm{Q}^{3}-1.0195 \mathrm{Q}^{2}-39761=0$

As this equation with power 3 so its solution will give three possible values for Q. Computer software called Mathematica was used to solve this equation. Following are the three computed values for Q:

$\mathrm{Q}=-15.6707-187.231$

$\mathrm{Q}=15.6707+187.231$

$\mathrm{Q}=1126.34$

The first two values are complex numbers so we ignore them and consider the third value, which is a real number (1126.34 mounds).

The ATC reaches its minimum when output level is 1126.34 mounds. As stated earlier that MC $=$ ATC at the point where ATC reaches its minimum. Now substituting $\mathrm{Q}=1126.34$ in ATC function.

$$
\begin{aligned}
& \mathrm{ATC}=0.0005 \mathrm{Q}^{2}-1.0195 \mathrm{Q}+988.2+\frac{39761}{\mathrm{Q}} \\
& =0.0005(1126.34)^{2}-1.0195(1126.34)+988.2+\frac{39761}{1126.34} \\
& =509.52
\end{aligned}
$$

From economic theory we know that $\mathrm{MC}=\mathrm{P}$ (Price of output) for optimal level of output. $\mathrm{P}$ is exogenous variable (whose value can be determined outside the model). As we have data for price of various grades, so we pool that data and find the average price as a whole. This way, we get the value for $\mathrm{P}$ and it is Rs.753/- per mound of milk. Therefore, we can find out the optimal level of output by equating MC to P.

$\mathrm{MC}=\mathrm{P}$

$$
\begin{aligned}
& 1.5 \times 10^{-3} \mathrm{Q}^{2}-2.039 \mathrm{Q}+988.2=753 \\
& 1.5 \times 10^{-3} \mathrm{Q}^{2}-2.039 \mathrm{Q}+988.2-753=0
\end{aligned}
$$

Now using quadratic formula, the values of $\mathrm{Q}$ can be determined. As quadratic equation gives two values, so we get two values for $\mathrm{Q}$.

$\mathrm{Q}=1232, \mathrm{Q}=-127.33$

As output cannot be negatives, so we ignore the second value of $\mathrm{Q}$ and accept the first value for $\mathrm{Q}$. Hence the optimal level of output is 1232 mounds. It is important to note that none of the respondent operates that optimal level. Thus, the results show that all the milk producers in the research area operate at level where ATC is still decreasing (i.e. irrational stage of production to stop).

\section{Conclusion}

This study was conducted in Timergara District Dir Lower to estimate cost of milk production. The study shows that average value of dry and milking buffaloes was 2 and 42 respectively while the average milk production per buffalo was 0.11 mounds. The major cost components of milk production were green fodder, dry fodder, concentrates, medicines, management, equipment, building and other miscellaneous. The total fixed cost (TFC) and average variable cost (AVC) per farm was 39761 and 468.51 rupees respectively. The marginal cost (MC) was minimum at output level 680 and the average variable cost (AVC) was at minimum i.e. Rs.468. The optimal level of milk production was 1232 mounds.

\section{References}

[1] Govt: of Pakistan. (2009-10) Economic Survey of Pakistan Bureau of Statistics Economic Affair Division, Ministry of Food Agriculture and Livestock, Islamabad, Pakistan, pp.2 4.

[2] Muhammad,.M.A. (1997) 'Economic analysis of milk production in district Okara' Pakistan Veterinary Journal, pp. 135-148.

[3] Khan, M. (1999) 'Economics of Milk production and marketing in the Development of Pakistan-With special reference to Peshawar District' Unpublished Ph.D Thesis, University of Wales, Aberystwyth, UK.

[4] Khan,.M, Kanes K. Rajah and Michael Haines. (1998) 'An analysis of strategies and efficiency in the milk production systems in Peshawar District KPK, Pakistan”, Journal of the University of Wales Agricultural Society, P.49-70.

[5] Bouquiaux, J.M and R.Hellemans. (1998) Economic analysis of milk production in Belgium. Brussels, Centrum-economics

[7] Kalra, K.K., Rajvir. S, .Anil., Singh, R. and Chauhan,.R. (1995) 'Economic analysis of milk production and disposal in rural areas of Haryana', Indian Journal of Dairy Science. Pp.546-555

[8] Singh, R.P.,Bhatnagar and Singh,B. (1995) 'Economic efficiency of milk production system under rural conditions', Indian Journal of Animal Research. pp.27-32

[9] Sharma, J.P and .Singh, R.V. (1994) 'An economic analysis of milk production by different breeds of milch animals in humidtemperate zone of Himachal Pradesh Indian Journal-of-Dairy-Science.pp.24-47.

[10] Dev,. R..Gupta and Raj, D. (1994) 'An economic analysis of milk production in Churu district of Rajasthan'. IndianJournal-of-Dairy-Science. Pp.749-755.

[11] Khan,. M. (1992) 'Estimation of Dual cost function for milk production in districtThatta, Sindh',. Sarhad Journal of Agriculture vol. 8. (2). 